\title{
BMJ Open Factoring in weather variation to capture the influence of urban design and built environment on globally recommended levels of moderate to vigorous physical activity in children
}

\author{
Tarun Reddy Katapally, ${ }^{1,2}$ Daniel Rainham, ${ }^{3}$ Nazeem Muhajarine $e^{2,4}$
}

To cite: Katapally TR, Rainham D, Muhajarine N. Factoring in weather variation to capture the influence of urban design and built environment on globally recommended levels of moderate to vigorous physical activity in children. BMJ Open 2015;5:e009045. doi:10.1136/bmjopen-2015009045

- Prepublication history for this paper is available online. To view these files please visit the journal online (http://dx.doi.org/10.1136/ bmjopen-2015-009045).

Received 16 June 2015 Revised 2 October 2015 Accepted 16 October 2015

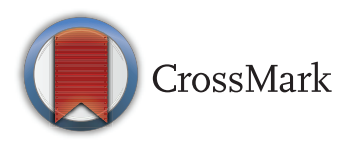

\footnotetext{
${ }^{1} J o h n s o n-S h o y a m a$ Graduate School of Public Policy, University of Regina, Regina, Saskatchewan, Canada ${ }^{2}$ Community Health \& Epidemiology, University of Saskatchewan, Saskatoon, Saskatchewan, Canada ${ }^{3}$ Environmental Science, Dalhousie University, Halifax, Nova Scotia, Canada ${ }^{4}$ Saskatchewan Population, Health and Evaluation Research Unit, Saskatoon, Saskatchewan, Canada
}

Correspondence to Dr Tarun Reddy Katapally; tarun.katapally@uregina.ca

\section{ABSTRACT}

Objectives: In curbing physical inactivity, as behavioural interventions directed at individuals have not produced a population-level change, an ecological perspective called active living research has gained prominence. However, active living research consistently underexplores the role played by a perennial phenomenon encompassing all other environmental exposures-variation in weather. After factoring in weather variation, this study investigated the influence of diverse environmental exposures (including urban design and built environment) on the accumulation of globally recommended moderate to vigorous physical activity levels (MVPA) in children.

Design: This cross-sectional observational study is part of an active living initiative set in the Canadian prairie city of Saskatoon. As part of this study, Saskatoon's neighbourhoods were classified based on urban street design into grid-pattern, fractured grid-pattern and curvilinear types of neighbourhoods. Moreover, diverse environmental exposures were measured including, neighbourhood built environment, and neighbourhood and household socioeconomic environment. Actical accelerometers were deployed between April and June 2010 (spring-summer) to derive MVPA of 331 10-14-year-old children in 25 1-week cycles. Each cycle of accelerometry was conducted on a different cohort of children within the total sample and matched with weather data obtained from Environment Canada. Multilevel modelling using Hierarchical Linear and Non-linear Modelling software was conducted by factoring in weather variation to depict the influence of diverse environmental exposures on the accumulation of recommended MVPA.

Results: Urban design, including diversity of destinations within neighbourhoods played a significant role in the accumulation of MVPA. After factoring in weather variation, it was observed that children living in neighbourhoods closer to the city centre (with higher diversity of destinations) were more likely to accumulate recommended MVPA.

Conclusions: The findings indicate that after factoring in weather variation, certain types of urban design are more likely to be associated with MVPA accumulation.

\section{Strengths and limitations of this study}

- The study shows that weather variation could be captured even in a single seasonal transition.

- After factoring in weather variation, the study establishes an association between urban design and the likelihood of children accumulating globally recommended levels of moderate to vigorous physical activity.

- The study highlights that different types of urban design could facilitate active living in children in different weather conditions.

- These findings not only have implications for conducting active living research, but also for policy interventions that focus on creating active urban communities.

- However, the study's findings are limited by cross-sectional design.

\section{INTRODUCTION}

Physical activity's (PA) benefits in preventing non-communicable diseases and promoting mental well-being in children have been well established. ${ }^{12}$ Despite this, physical inactivity has reached pandemic levels, with a majority of children not accumulating recommended levels of moderate to vigorous PA (MVPA).$^{3-6}$ Current global PA guidelines recommend that children aged 5-17 years should accumulate at least $60 \mathrm{~min}$ of MVPA every day. ${ }^{5}$ In curbing physical inactivity, as behavioural interventions directed at individuals have not produced a change at the population level, active living interventions that aim to modify urban design and built environment to facilitate PA have gained prominence.

Active living evidence in children thus far indicates some consistent findings, where safety (especially for girls), perception of recreational environment and opportunity for active transportation have been positively 
associated with PA. ${ }^{7-13}$ Recent evidence has revealed a more complex picture, where the roles of multilevel environmental determinants (urban design, neighbourhood built and social environment, school environment, and home environment) on PA have been emphasised. ${ }^{14-16}$

Nevertheless, active living interventions have underexplored a phenomenon that perennially interacts with all other environmental factors-weather variation. The significance of weather variation's influence on PA is especially important in temperate and continental climatic zones (Köppen-Geiger climate classification) due to a wide variation in seasonal weather in these regions. ${ }^{17}$ Studies that have explored seasonal weather variation's exclusive influence on PA in populations inhabiting these regions report a fairly stable and expected observation of higher PA in warmer months, among all age groups. ${ }^{18-22}$

In Canada, the majority of the population experiences a wide variation in seasonal temperatures and weather conditions. ${ }^{17} 2324$ Within Canada, prairie provinces like Saskatchewan, where this study was conducted, are known for particularly extreme variations in seasonal weather, ${ }^{23}{ }^{24}$ and there is evidence to indicate that the relationship between seasonality and PA is stronger in Saskatchewan. ${ }^{22}$

However, weather variation can influence PA even within seasons and during seasonal transitions. Research on the influence of weather on PA in children and adolescents provides further insight into influence of weather variation on PA within seasons. Evidence from a Canadian 5-year longitudinal study of adolescent PA showed that higher temperatures increased PA, and higher rainfalls reduced $\mathrm{PA}{ }^{25}$ Similarly, a study of the impact of rainfall and school break time policies on PA in 9-10-year-old British children revealed that rainfall is negatively associated with PA. ${ }^{26}$

Even though evidence on the influence of weather variation on PA points towards warmer weather being positively associated and rainy weather being negatively associated with PA in temperate and continental climatic zones, most studies thus far have exclusively focused on weather, a non-modifiable entity, instead of understanding how diverse environmental exposures influence PA after factoring in weather variation. More importantly, in developing active urban communities, it is imperative that urban planning policy is conceptualised by taking into account how different types of urban design and built environment interact with weather variation to influence PA accumulation in children. Furthermore, in capturing weather variation, there has been an under exploration of the complex and interrelated dynamics of key variables such as temperature, wind and precipitation. ${ }^{18-22} 25-27$

This study first conceptualises weather as a complex entity consisting of several interrelated elements that can be combined to categorise localised weather patterns. Thereafter, by factoring in localised weather and neighbourhood and household socioeconomic environment, this study hypothesises that urban and built environment significantly influence globally recommended levels of MVPA in children aged 10-14 years.

\section{METHODS}

The study is part of an active living research initiative in Saskatoon, Saskatchewan, Canada (http://www. smartcitieshealthykids.com). The study protocol was approved by the University of Saskatchewan's Research Ethics Board.

\section{Urban design of Saskatoon}

Presently Saskatoon's metropolitan area population of 260600 is spread across 65 well-defined neighbourhoods ${ }^{28}$ where the city plays a major role in urban planning including the geographic allocation of commercial, residential and institutional establishments.

The neighbourhoods designed prior to 1930 surround the city centre and follow a traditional grid-patterned street design (figure 1-Planning Era 1), typified by higher density, mixed-use neighbourhoods connected by straight, intersecting streets and back alleys. The semisuburban neighbourhoods built between 1931 and 1966 follow a fractured grid-pattern (figure 1-Planning Era 2). They are predominantly residential, with lower density and become progressively car-oriented as the distance from the urban centre increases. Finally, the suburban neighbourhoods built after 1967 follow curvilinear street patterns (figure 1-Planning Era 3), characterised by lowdensity, almost exclusively residential and highly caroriented configurations. Working with the City of Saskatoon's Neighbourhood Planning Department, our Smart Cities Healthy Kids research team has validated the three types of neighbourhoods belonging to the three different planning eras. ${ }^{29}$

\section{Neighbourhood selection and recruitment}

The neighbourhood selection and recruitment were part of the Smart Cities Healthy Kids initiative. The sampling frame for recruiting children consisted of all 60 residential neighbourhoods in 2010 in Saskatoon categorised into the three types of neighbourhoods (figure 1). Working with our public and Catholic school board partners, all schools in Saskatoon situated in all three types of neighbourhoods were invited to participate in the study. The recruitment was conducted through 30 elementary schools that accepted to participate and the total study sample was representative of all 60 neighbourhoods. Working with the schools, we identified four classrooms at each elementary school (grades 5-8) and each school was provided with letters of consent to be given to each potential participant to deliver to their primary caregiver. In order to participate in the study, caregivers returned the signed forms to their child's homeroom teacher. It was made explicit in the consent form that caregivers or children would be able to opt out of 
Saskatoon Neighbourhood Planning Eras 1900 - 2009

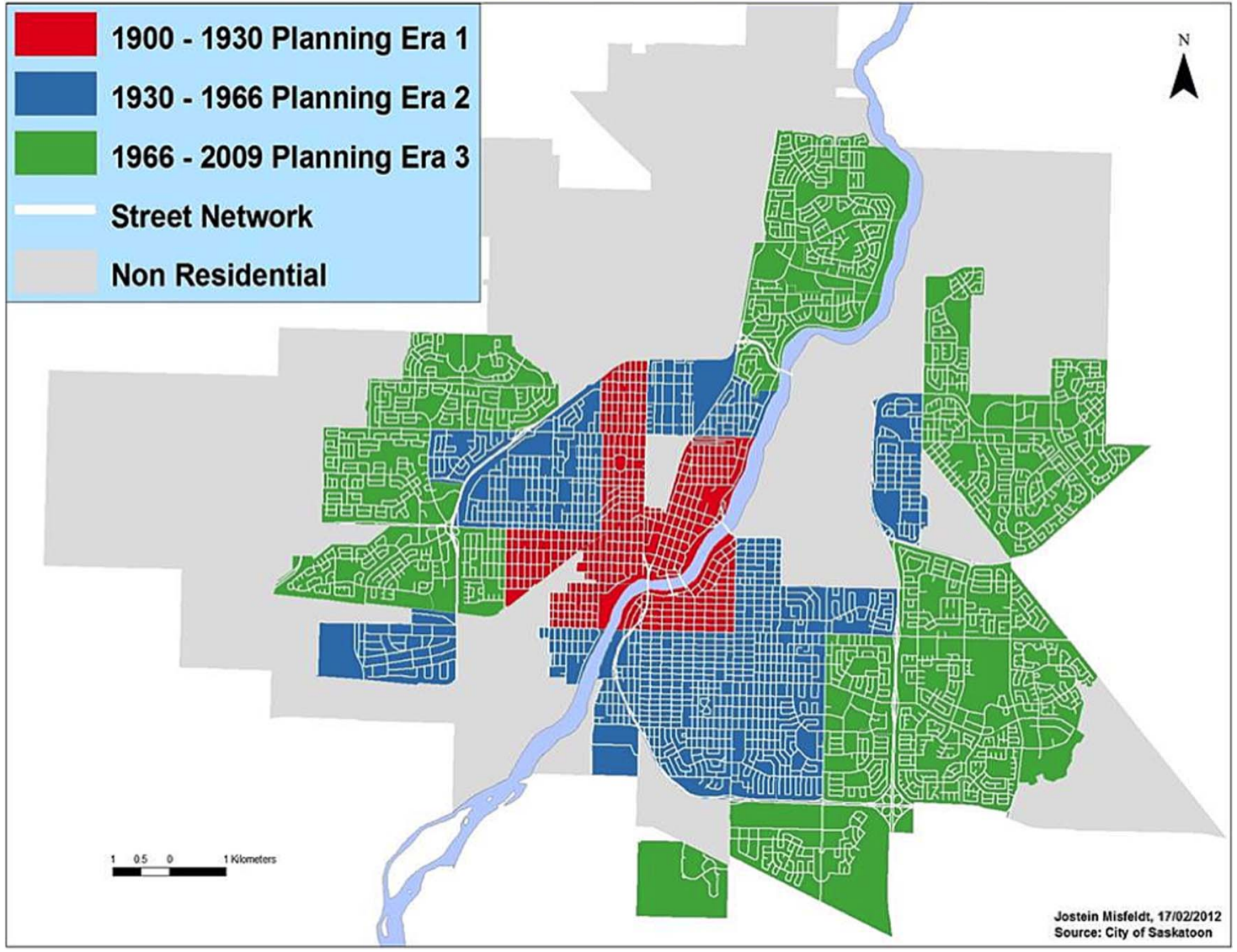

Figure 1 Urban design of Saskatoon depicting the three types of neighbourhoods (grid; fractured grid; curvilinear-green).

participating at any time up until the data were pooled. Children were also provided an opportunity to decline participation even after obtaining parental consent. Of the 1610 children aged $10-14$ years who agreed to participate in the Smart Cities Healthy Kids initiative, 455 children agreed to participate in accelerometry. This study exclusively focuses on children who participated in accelerometry.

\section{Built environment measures}

In 2009, specific built environment characteristics of all residential neighbourhoods in Saskatoon were measured utilising two replicable tools called the Neighbourhood Active Living Potential $^{30}$ and the Irvine-Minnesota Inventory. ${ }^{31}$ Together, these two tools were used to measure neighbourhood safety from traffic and crime, density and diversity of destinations, activity friendliness, attractiveness and pedestrian access.

\section{Census-based measures}

Neighbourhood level socioeconomic variables were derived from 2006 Statistics Canada Census data ${ }^{32}$ and 2010 G5 Census projections ${ }^{33}$ to account for neighbourhood social environment. These included variables such as neighbourhood dwelling value, neighbourhood household income and neighbourhood unemployment rate.

\section{Individual and household data}

In 2010, prior to deploying accelerometers, a questionnaire was administered to 455 children to capture their perception of a range of factors (household, parental, peer and neighbourhood) that influence PA. The questionnaire was pilot tested and revised as appropriate prior to field implementation. The questionnaire contained items such as: 'In the last 30 days, how often have your family members provided transportation to a place where you can do PA?' and 'During a typical week, how often did your friends ask you to walk or bike to school or to a friend's place?'

\section{Accelerometry}

Actical accelerometers (Mini Mitter Co., Inc., Bend, Oregon, USA) were deployed through schools to capture activity data of 455 children who completed the questionnaire. Children were visited at their respective schools and were asked to wear the accelerometer equipped belt around their waist to maintain proper positioning (ie, posterior to the right iliac crest of the hip) for seven consecutive days. They were advised to remove the accelerometers during night time sleep and during any water-based activities. The devices were operationalised to measure data at 12:00 on the day following device deployment (ie, almost a full day after the device was deployed) to minimise the potential for subject 
reactivity within the first day of wearing the accelerometer. Accelerometers were preprogrammed to measure movement in $15 \mathrm{~s}$ epochs in order to capture the sporadic nature of children's activity.

The raw accelerometer data were analysed using KineSoft V.3.3.63 (KineSoft, Loughborough, UK) to derive activity intensities using cut-points specific to the study sample's age group-sedentary behaviour (SB): $<100$ counts/min; light physical activity (LPA): 100 to $<1500$ counts $/ \mathrm{min}$; MVPA: $\geq 1500$ counts $/ \mathrm{min}^{.34-36}$ The accelerometers and cut-points used in this study are the same as those used in the 2007-2009 Canadian Health Measures Survey, whose accelerometry results depicted activity patterns in a nationally representative sample of children in Canada. ${ }^{6}$ Furthermore, using the accelerometer sample of the 2007-2009 Canadian Health Measures Survey, operational definitions and data reduction techniques were developed by Colley et $a l^{37}$ Valid data for our study were derived by utilising these population and device-specific (ie, actical accelerometers) operational definitions and data reduction techniques, and taking into account established evidence in conducting accelerometry on large samples of children. ${ }^{37} 38$

Generation of valid data is essential to exclude days of accelerometry from the analysis when the participants do not wear the device for a period of time deemed sufficient to interpret levels of activity. ${ }^{37} \mathrm{~A}$ valid day was defined as a day of accelerometry with 10 or more hours of wear-time. ${ }^{38}$ Daily wear-time was estimated by subtracting non-wear-time of a particular accelerometry day from $24 \mathrm{~h}$. It was determined that non-wear-time would be a period of at least 60 consecutive minutes of zero accelerometer counts, including up to $2 \mathrm{~min}$ of counts between 0 and $100 .{ }^{37}$ The final sample consisted of children with at least four valid days including at least one valid weekend day, that is, the valid sample $(\mathrm{N}$ : 331; boys: 166; girls: 165 (Age 10: boys: 42; girls: 28) (Age 11: boys: 41; girls: 50) (Age 12: boys: 40; girls: 45) (Age 13: boys: 29; girls: 35 ) (Age 14: boys: 13; girls: 8 ).

However, even within valid data, there is a chance for systematic variation in daily wear-time, within (on different days of accelerometer use) and between participants. The systemic variation occurs because even though participants are asked to wear accelerometers from the time they wake up in the morning until the time they go to bed at night, every participant wears or removes the accelerometer at her/his discretion, thus potentially introducing a random or non-random measurement bias to activity measurement. We have previously developed a methodology to control for wear-time variation and minimise measurement bias by standardisation of valid data. ${ }^{39} 40$ The same methodology has been replicated in this study to standardise valid data.

\section{Integration of localised weather with cross-sectional accelerometry}

Accelerometer data were obtained in 251 week cycles between 28 April and 11 June 2010 (which represented a 45-day transition period from spring to summer). Each 1 week cycle of accelerometry was conducted on a different cohort of children within the total sample, with each cohort consisting of a different set of children. To match the accelerometry period, detailed weather data for the days between 28 April and 11 June 2010, were obtained from Environment Canada. ${ }^{41} 42$

Saskatoon experiences four distinct seasons, with average temperatures of $3.4^{\circ} \mathrm{C}$ in spring, $17.2^{\circ} \mathrm{C}$ in summer, $3.2^{\circ} \mathrm{C}$ in autumn and $-14^{\circ} \mathrm{C}$ in winter. The city's precipitation levels are relatively low and winds usually blow from the northwest with an average speed of $15 \mathrm{~km} / \mathrm{h}$ year round. ${ }^{43}{ }^{44}$ To capture the transition from Spring to Summer, extensive exploration of the weather data was conducted to identify daily values of key weather variables corresponding to the accelerometry period: maximum temperature (Celsius), precipitation (millimetres), speed of maximum wind gust $(\mathrm{km} / \mathrm{h})$ and hours of illumination. ${ }^{27}$

Descriptive analyses were conducted to understand the distribution (ie, mean, median, SD of daily values of the selected weather variables during the 45 days of accelerometry. Daily values of each of these weather variables were aggregated to their corresponding 1 week cycle of accelerometry to calculate their mean weekly values. Thereafter, a decision rule was applied where $1 \mathrm{SD}$ of the distribution of daily weather values for the 45 days of accelerometry was set as the cut-point. Using this cut-point, mean weekly values for each weather variable were categorised as follows: temperature: $\geq 1 \mathrm{SD}=$ Warm, $\quad<1 \mathrm{SD}=$ Cold; precipitation: $\quad \geq 1 \mathrm{SD}=$ Wet , $<1 \mathrm{SD}=$ Dry; speed of maximum wind gust: $\geq 1 \mathrm{SD}=$ Windy, $<1 \mathrm{SD}=$ Calm.

Finally, based on these six categories, one of the following four localised weather patterns was assigned to each week of accelerometry (weekly weather): Warm-Wet-Calm, Cold-Dry-Calm, Cold-Dry-Windy and Cold-Wet-Calm. Although, mathematically, the possible combination of weather patterns is higher than four, it is important to highlight that the classification of localised weather is based on actual weather recorded during the period of accelerometry. As the range (2.26) and SD (0.69) of hours of illumination during the 45 days of accelerometry was negligible, hours of illumination was excluded from the classification of localised weather patterns and was instead included as an independent variable in multivariable analyses.

\section{Statistical analyses}

Using data from all the measures mentioned, an extensive set of predictors were derived taking into account the hierarchical nature of data distribution: neighbourhood level variables (level 2) and individual level variables (level 1)-table 1. Current PA guidelines recommend that children aged 5-17 years should accumulate at least $60 \mathrm{~min}$ of MVPA every day. ${ }^{5}$ Thus, all analyses were conducted with MVPA as the outcome variable. Analysis of variance was conducted to assess 
Table 1 Hierarchical distribution of predictors

\begin{tabular}{|c|c|c|c|}
\hline Hierarchy & Type of measures & $\begin{array}{l}\text { Examples of derived } \\
\text { variables }\end{array}$ & Instrument \\
\hline \multirow[t]{4}{*}{$\begin{array}{l}\text { Neighbourhood level } \\
\text { variables }\end{array}$} & Urban design & $\begin{array}{l}\text { Grid-pattern } \\
\text { Fractured grid-pattern } \\
\text { Curvilinear }\end{array}$ & Urban Planning \\
\hline & Built environment & $\begin{array}{l}\text { Diversity of } \\
\text { destinations }\end{array}$ & $\begin{array}{l}\text { Observation Tools: Neighbourhood } \\
\text { Active Living Potential and Irvine }\end{array}$ \\
\hline & & $\begin{array}{l}\text { Density of destinations } \\
\text { Safety from traffic } \\
\text { Safety from crime } \\
\text { Attractiveness } \\
\text { Pedestrian access } \\
\text { Universal accessibility } \\
\text { Activity friendliness }\end{array}$ & Minnesota Inventory \\
\hline & Neighbourhood social environment & $\begin{array}{l}\text { Dwelling value } \\
\text { Dwellings per acre } \\
\text { Household income }\end{array}$ & $\begin{array}{l}2006 \text { Statistics Canada Census and G5 } \\
2010 \text { Census Projections }\end{array}$ \\
\hline \multirow[t]{2}{*}{$\begin{array}{l}\text { Individual level } \\
\text { variables }\end{array}$} & $\begin{array}{l}\text { Children's perception of household, } \\
\text { neighbourhood, peer and parental } \\
\text { factors }\end{array}$ & $\begin{array}{l}\text { Transportation support } \\
\text { from family } \\
\text { Peer support to walk } \\
\text { or bike } \\
\text { Household } \\
\text { socioeconomic status } \\
\text { Parents' education }\end{array}$ & $\begin{array}{l}\text { Smart Cities Healthy Kids } \\
\text { Questionnaire }\end{array}$ \\
\hline & Activity measures & $\begin{array}{l}\text { Moderate to vigorous } \\
\text { physical activity } \\
\text { Light physical activity } \\
\text { Sedentary behaviour }\end{array}$ & Accelerometry \\
\hline
\end{tabular}

group differences in MVPA between the four types of localised weather patterns (Warm-Wet-Calm, Cold-Dry-Calm, Cold-Dry-Windy and Cold-Wet-Calm), and between children residing in different types neighbourhoods. Thereafter, to determine the odds of children accumulating recommendation levels of PA, daily MVPA was dichotomised at $60 \mathrm{~min}$ to build fixed effects multilevel logistic regression models utilising Hierarchical Linear and Nonlinear Modelling software.

All the independent variables included in multilevel modelling were significant at the bivariate stage. Model
1 depicts the influence of localised weather patterns (with Warm-Wet-Calm category as the reference) and as well as the influence of other individual level variables. Model 2 is the final model depicting the influence of neighbourhood and individual level variables. Only significant results from the final model are discussed here.

\section{RESULTS}

A majority of the children did not meet recommended PA guidelines (figure 2). The study sample was representative of neighbourhoods with all three types of urban
Figure 2 Proportion of children meeting recommended physical activity guidelines.

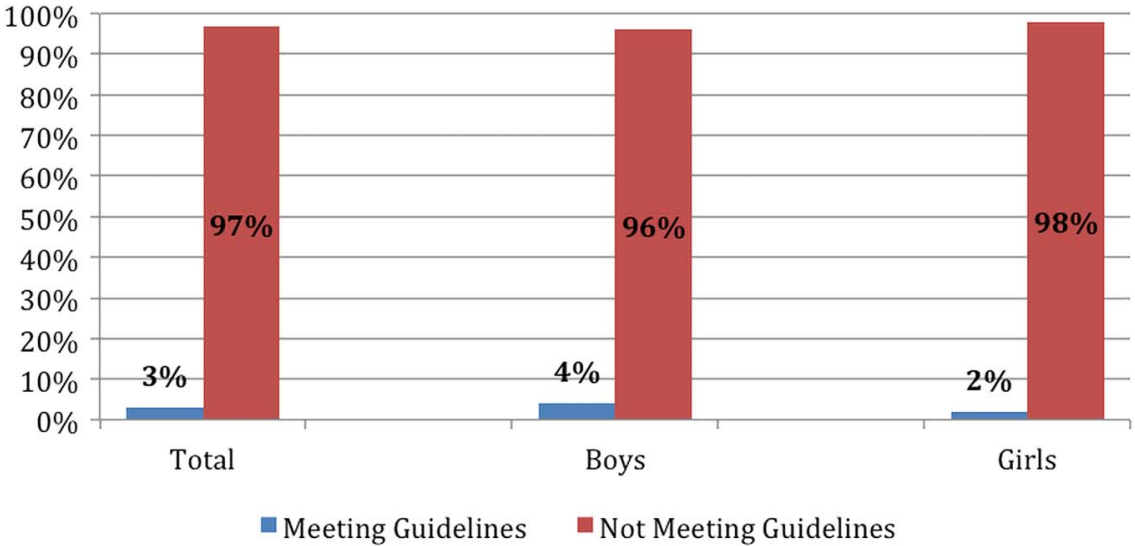


design (figure 1-grid, fractured grid and curvilinear), with boys and girls of all age groups (10-14 years) being sampled from each type of neighbourhood. Before factoring in weather variation, descriptive distribution of activity intensities across the three types of neighbourhoods revealed that children in fractured grid-pattern neighbourhoods accumulated lower MVPA and higher sedentary time in comparison with children in the gridpattern and curvilinear neighbourhoods (table 2).

Between the four types of localised weather patterns, Warm-Wet-Calm weather was associated with significantly higher MVPA, whereas Cold-Dry-Windy weather was associated with significantly lower MVPA (data not shown here). Another significant observation was that the children residing in neighbourhoods with fractured gridpattern accumulated lower MVPA during all types of localised weather patterns (table 3 ).

The multilevel multivariable model depicts the influence urban design and built environment on the likelihood of accumulation of recommended levels of MVPA by factoring in localised weather (table 4 ).

Boys were more likely to accumulate recommended MPVA than girls and localised weather did play a significant role in influencing MVPA accumulation. In comparison with children who experienced Warm-Wet-Calm weather, children who experienced Cold-Wet-Calm weather were less likely to accumulate recommended MVPA (OR=0.44; 95\% CI 0.01 to 0.92$)$. Another factor that reiterated the findings in descriptive analyses was that children who experienced Cold-Dry-Windy weather were less likely to accumulate recommended MVPA $(\mathrm{OR}=0.78$; CI 0.01 to 0.83$)$ in comparison with children who experienced Warm-Wet-Calm weather.

In terms of urban design of Saskatoon, again reiterating descriptive findings, multilevel modelling showed that children residing in fractured grid-pattern neighbourhoods were less likely to accumulate recommended MVPA (OR=0.45; CI 0.22 to 0.93) in comparison with children living in grid-pattern neighbourhoods. Whereas children residing in neighbourhoods with greater diversity of destinations were more likely to accumulate recommended MVPA (OR=2.09; CI 1.14 to 3.83) in comparison with children residing in neighbourhoods with lower diversity of destinations. Overall, after factoring in weather variation, children residing in fractured gridpattern neighbourhoods had the least likelihood of accumulating recommended MVPA.

\section{DISCUSSION}

As epidemiological investigations of active living to date have either concentrated exclusively on weather, or built environment, this study's objective is the inclusion of weather variation in understanding how urban design and built environment influence the accumulation of globally recommended levels of MVPA in children. In addressing the gap of non-inclusion of weather variation in active living research, the methodological approach in this study focused on conceptualising weather as a complex entity consisting of several interrelated elements that can be combined to categorise localised weather patterns. Localised weather patterns have been effectively utilised in other areas of health research, ${ }^{45}$ and this study adopted similar approaches by integrating cross-sectional accelerometry with localised weather patterns, a method that has previously not been employed.

Integration of cross-sectional accelerometry with localised weather patterns depicted that weather variation influences children's MVPA even in a single seasonal transition (spring to summer). Moreover, after factoring in localised weather patterns, urban design and built environment influenced children's MVPA, where MVPA accumulation varied significantly between children residing in different types of neighbourhoods.

Descriptive results depicted a consistent pattern of Warm-Wet-Calm weather being associated with higher MVPA accumulation and Cold-Dry-Windy weather being associated with lower MVPA accumulation. It is apparent that exposure to higher daily temperatures played a role in higher MVPA accumulation. This observation corroborates the established evidence ${ }^{18-222526}$ that overall, in temperate climatic zones, a rise in temperature facilitates higher PA. However, the patterns observed by combining individual weather variables to create localised weather portray a more nuanced picture.

For instance, even though studies indicate that PA accumulation decreases with increasing precipitation, ${ }^{25}{ }^{26}$ after factoring in precipitation, Warm-Wet-Calm weather was associated with higher MVPA and Cold-Dry-Windy weather was associated with lower MVPA. In Warm-Wet-Calm and Cold-Dry-Windy weather patterns, irrespective of the amount of precipitation (wet or dry), temperature and speed of maximum wind gust influenced MVPA accumulation. These observations not only underline the complexity of weather, but also the need to account for the interrelatedness and dynamics of specific characteristics such as temperature, wind speed and precipitation. ${ }^{27}$

When MVPA accumulation was compared between children who experienced the same type of localised weather, a clear pattern emerged. Children residing in neighbourhoods with fractured grid-pattern urban design consistently accumulated less MVPA in comparison with children residing in neighbourhoods with gridpattern and curvilinear urban design. The grid-pattern neighbourhoods surrounding the city centre, by virtue of their mixed land-use (combination of commercial, residential, institutional establishments), possess greater density and diversity of destinations, are less caroriented, and more pedestrian friendly. ${ }^{46}$ The observation that mixed land-use urban design positively influences the accumulation of more MVPA in children aged 10-14 years corroborates findings from a systematic review that showed mixed land-use to be a strong predictor of PA among children and adolescents. ${ }^{14}$

However, curvilinear neighbourhoods, which do not have mixed-land use and are distinct from grid-pattern 
Table 2 Descriptive characteristics of the study sample depicted across urban design

\begin{tabular}{|c|c|c|c|c|}
\hline Variables & Total & Grid & Fractured grid & Curvilinear \\
\hline Sampled schools & 30 & 6 & 10 & 14 \\
\hline Total sample & 331 & 95 & 100 & 136 \\
\hline Boys & 166 & 45 & 53 & 68 \\
\hline Girls & 165 & 50 & 47 & 68 \\
\hline Age 10 & 70 & 16 & 25 & 29 \\
\hline Age 11 & 91 & 32 & 22 & 37 \\
\hline Age 12 & 85 & 27 & 26 & 32 \\
\hline Age 13 & 64 & 13 & 23 & 28 \\
\hline Age 14 & 21 & 7 & 4 & 10 \\
\hline $\begin{array}{l}\text { Mean age (SD; } \\
\text { Min,Max) }\end{array}$ & $11.6(1.1 ; 10,14)$ & $11.6(1.1 ; 10,14)$ & $11.5(1.2 ; 10,14)$ & $11.63(1.2 ; 10,14)$ \\
\hline $\begin{array}{l}\text { Mean body mass } \\
\text { index (SD; } \\
\text { Min,Max) }\end{array}$ & $19.9(4 ; 13.4,35.9)$ & $19.8(4.2 ; 14,35.9)$ & $20.3(4.2 ; 13.4,34.3)$ & $19.7(3.7 ; 14.2,33.8)$ \\
\hline $\begin{array}{l}\text { Mean } \\
\text { accelerometer } \\
\text { Wear-time/day } \\
\text { (SD; Min,Max) }\end{array}$ & $796.3(51.1 ; 653.3,930.2)$ & $794(53.1 ; 680.8,930.2)$ & 797 (53.3; 653.3,915) & $797.3(48.1 ; 684.5,910.6)$ \\
\hline $\begin{array}{l}\text { Mean MVPA/day } \\
\text { (SD; Min,Max) }\end{array}$ & $71.2(31.8 ; 8,234.5)$ & $72.8(33.7 ; 8,178.1)$ & $67.3(32.9 ; 13.3,234.5)$ & $73.1(29.4 ; 16.6,182)$ \\
\hline $\begin{array}{l}\text { Mean SB/day } \\
\text { (SD; Min,Max) }\end{array}$ & $540.2(64.8 ; 317.4,691.3)$ & $537.8(68.9 ; 317.4,682.6)$ & $546(70.5 ; 344,691.3)$ & $537.3(57 ; 379.7,663.4)$ \\
\hline $\begin{array}{l}\text { Mean LPA/day } \\
\text { (SD; Min,Max) }\end{array}$ & 184.7 (38.9; 92.5,311.6) & $183.3(39.1 ; 104.4,282.5)$ & $183(40.9 ; 92.5,311.6)$ & $187(37.4 ; 98$ 294.6) \\
\hline
\end{tabular}

neighbourhoods in being highly car-oriented, were also associated with higher MVPA. Curvilinear neighbourhoods, though highly car-oriented, represent the higher socioeconomic areas of Saskatoon with greater safety from crime and traffic and this could possibly explain the higher accumulation of MVPA in these neighbourhoods. Nevertheless, the findings suggest that two contrasting types of urban design can have a positive influence on MVPA accumulation in children after factoring in localised weather patterns.

This influence of urban design and built environment on MVPA was further explored by factoring in localised weather patterns in multilevel models that depicted the influence of diverse environmental exposures on the accumulation of recommended levels of MVPA in children. Reiterating descriptive results, multilevel modelling showed that children residing in semisuburban fractured grid-pattern neighbourhoods were less likely to accumulate recommended MVPA in comparison with children residing in grid-pattern neighbourhoods located near the city centre.

The usage of the term 'grid-pattern' is due to the structure of road networks in these neighbourhoods that have multiple intersections and interconnected streets,

Table 3 ANOVA testing group differences in MVPA between different types of neighbourhoods stratified by localised weather patterns

\begin{tabular}{|c|c|c|c|c|c|c|c|}
\hline \multicolumn{4}{|c|}{ MVPA accumulation-Warm-Wet-Calm } & \multicolumn{4}{|c|}{ MVPA accumulation-Cold-Dry-Windy } \\
\hline & Grid & Fractured & Curvilinear & & Grid & Fractured & Curvilinear \\
\hline Grid & 0.00 & 3.67 & -5.46 & Grid & 0.00 & 0.00 & NA \\
\hline Fractured & -3.67 & 0.00 & $-9.13^{\star \star \star}$ & Fractured & 0.00 & 0.00 & NA \\
\hline Curvilinear & 5.46 & $9.13^{\star \star \star}$ & 0.00 & Curvilinear & NA & NA & 0.00 \\
\hline \multicolumn{4}{|c|}{ MVPA accumulation-Cold-Dry-Calm } & \multicolumn{4}{|c|}{ MVPA accumulation-Cold-Wet-Calm } \\
\hline & Grid & Fractured & Curvilinear & & Grid & Fractured & Curvilinear \\
\hline Grid & 0.00 & 3.07 & -4.41 & Grid & 0.00 & $6.31^{\star \star \star}$ & 3.78 \\
\hline Fractured & -3.07 & 0.00 & $-7.49^{\star \star \star}$ & Fractured & $-6.31^{\star \star \star}$ & 0.00 & -2.52 \\
\hline Curvilinear & 4.41 & $7.49^{\star \star \star}$ & 0.00 & Curvilinear & -3.78 & 2.52 & 0.00 \\
\hline
\end{tabular}


Table 4 Multilevel logistic regression modelling factoring in weather variation to predict the influence of urban design and built environment on MVPA (mean daily MVPA dichotomised at $60 \mathrm{~min}$ )

\begin{tabular}{|c|c|c|c|c|c|c|}
\hline \multirow[b]{2}{*}{ Variables } & \multicolumn{2}{|c|}{ Null model } & \multicolumn{2}{|c|}{ Model 1} & \multicolumn{2}{|c|}{ Model 2} \\
\hline & OR & $\mathbf{C l}$ & OR & $\mathbf{C l}$ & OR & $\mathbf{C l}$ \\
\hline Intercept & 1.72 & 1.34 to 2.12 & 1.13 & 0.61 to 2.87 & 0.26 & 0.00 to 16.72 \\
\hline Cold-Dry-Windy vs Warm-Wet-Calm & & & $0.58^{*}$ & 0.21 to 0.84 & $0.78^{\star \star}$ & 0.01 to 0.83 \\
\hline Cold-Dry-Calm vs Warm-Wet-Calm & & & 0.67 & 0.23 to 12.74 & 0.54 & 0.24 to 16.35 \\
\hline Cold-Wet-Calm vs Warm-Wet-Calm & & & $0.32^{*}$ & 0.16 to 0.78 & $0.44^{\star}$ & 0.01 to 0.92 \\
\hline Boys vs girls & & & $1.42^{\star}$ & 1.27 to 4.28 & $2.06^{\star \star}$ & 1.27 to 3.33 \\
\hline Age 11 vs age 10 & & & 0.63 & 0.28 to 9.42 & 0.82 & 0.41 to 7.63 \\
\hline Age 12 vs age 10 & & & 0.81 & 049 to 9.75 & 0.86 & 0.43 to 9.32 \\
\hline Age 13 vs age 10 & & & 0.42 & 0.56 to 19.42 & 0.67 & 0.32 to 22.42 \\
\hline Age 14 vs age 10 & & & 0.50 & 0.03 to 44.77 & 0.53 & 0.12 to 36.67 \\
\hline Fractured grid vs grid & & & & & $0.45^{\star *}$ & 0.22 to 0.93 \\
\hline Curvilinear vs grid & & & & & 0.59 & 0.11 to 2.73 \\
\hline Diversity of destinations to high vs low & & & & & $2.09^{\star \star}$ & 1.14 to 3.83 \\
\hline
\end{tabular}

Model 1 depicts the influence of localised weather patterns (with Warm-Wet-Calm category as the reference) and as well as the influence of other individual level variables. Model 2 is the final model depicting the influence of both neighbourhood and individual level variables. Only significant results from the final model are discussed in the results.

${ }^{*} \mathrm{p}<0.05 ;{ }^{* *} \mathrm{p}<0.01 ;{ }^{* * *} \mathrm{p}<0.001 .95 \% \mathrm{Cl}$.

MVPA, moderate o vigorous physical activity.

which ultimately provide greater access to the many destinations available due to mixed land-use. Greater density and street connectivity is associated with higher PA in adults, ${ }^{47}$ however, greater density and street connectivity bring increased volume of traffic, which is associated with lower PA in children. ${ }^{14}$ In this study, diversity of destinations and perceived safety from traffic were assessed using Irvine Minnesota Inventory. ${ }^{31}$ Perceived safety was lowest and diversity of destinations was greatest in grid-pattern neighbourhoods, yet the finding that 1014-year-old children in these neighbourhoods had higher likelihood of accumulating recommended MVPA requires further explanation.

In terms of the influence of weather, multilevel modelling reiterated descriptive results by depicting those children who experienced Cold-Dry-Windy and Cold-Wet-Calm weather were less likely to accumulate recommended MVPA in comparison with children who experienced Warm-Wet-Calm weather. If weather variation could affect PA even during a single seasonal transition, it is apparent that variation of weather throughout the year has a significant influence on active living. Moreover, as depicted in this study, to capture the complexity of weather variation it is imperative to take the interrelated nature of weather into consideration.

After factoring in weather variation and controlling for social environment at the neighbourhood and household level, urban design and built environment emerged as the key factors that influenced PA in children. More importantly, using multilevel logistic regression modelling an association has been established between mixed land-use urban design and the likelihood of accumulating recommended levels of MVPA in children aged 10-14 years. Moreover, after controlling for factors at the individual and neighbourhood level, boys were more likely to accumulate recommended
MVPA. This pattern reiterates existing evidence that boys are more active than girls, ${ }^{6}$ and points towards the development of gender-specific active living programmes and policies that aim to reduce the existing gap in active living between boys and girls.

The study does have limitations, including the crosssectional design. Even though objective PA data is obtained through accelerometers, the lack of social (ie, with whom the activity is accumulated) and spatial context related to activity accumulation poses difficulty in establishing accurate understanding. Thus, even though associations between PA accumulation and urban design have been established, these findings do not objectively elaborate how activity is accumulated within different environmental contexts or where (neighbourhood, indoor/outdoor, playground, recreational facility, etc.) activity is accumulated.

For example, obtaining social and spatial context would enable the understanding of independent mobility of children, an active living indicator which is currently poorly understood. ${ }^{3}$ Studies are now emerging which utilise ecological momentary assessments ${ }^{48}$ and global positioning systems ${ }^{49}$ to understand the complex social and spatial associations of activity accumulation. These advances, when combined with accelerometry, would provide the methodological depth to tease out the complex pathways that determine activity accumulation.

In conclusion, weather variation is a critical factor that needs to be accounted for in active living research and this could be achieved by integrating localised weather patterns with existing cross-sectional accelerometry data. Ultimately, as weather is non-modifiable, the focus falls on understanding how diverse environmental exposures, especially urban design and built environment interact with weather variation to influence accumulation of PA throughout the year. 
As the health benefits of accumulation of recommended levels of MVPA are well established in all age groups, the evidence generated by this study has been translated to the urban planners in Saskatoon for the development of active urban neighbourhoods in future. Based on our findings, we have found that more than one type of urban design could facilitate active living in different weather conditions, however, the key factors that emerged were mixed land-use and safety. Moreover, urban planners in all jurisdictions should take into account the interaction between their location-specific weather patterns and the different types of urban design in developing neighbourhoods that moderate the influence of adverse weather and facilitate the influence of favourable weather on active living in children.

Acknowledgements The authors acknowledge the Smart Cities, Healthy Kids research team and staff. The authors also acknowledge the University of Regina's President's Publication Fund which enabled the payment of the open access fee.

Contributors TRK conceptualised the study, analysed and interpreted the data, and drafted all versions of the article. TRK is accountable to all aspects of this work and has provided his final approval for the study to be published. NM and DR played a key role in clarifying the conception of the study, interpreting the data and assisting in generating the final draft. NM and DR provide their approval for this work to be published and will be accountable to all aspects of this work.

Funding This work was supported by the Canadian Institutes of Health Research, the Heart and Stroke Foundation of Canada, and Rx\&D: Health Research Foundation.

Competing interests None declared.

Ethics approval University of Saskatchewan Research Ethics Board.

Provenance and peer review Not commissioned; externally peer reviewed.

Data sharing statement No additional data are available.

Open Access This is an Open Access article distributed in accordance with the Creative Commons Attribution Non Commercial (CC BY-NC 4.0) license, which permits others to distribute, remix, adapt, build upon this work noncommercially, and license their derivative works on different terms, provided the original work is properly cited and the use is non-commercial. See: http:// creativecommons.org/licenses/by-nc/4.0/

\section{REFERENCES}

1. Sothern MS, Loftin M, Suskind RM, et al. The health benefits of physical activity in children and adolescents: implications for chronic disease prevention. Eur J Pediatr 1999;158:271-4.

2. Janssen I, Leblanc AG. Systematic review of the health benefits of physical activity and fitness in school-aged children and youth. Int $J$ Behav Nutr Phys Act 2010;7:40.

3. Tremblay MS, Gray CE, Akinroye K, et al. Physical activity of children: a global matrix of grades comparing 15 countries. J Phys Act Health 2014;11(Supp 1): S113-25.

4. Hallal PC, Andersen LB, Bull FC, et al. Global physical activity levels: surveillance progress, pitfalls, and prospects. Lancet 2012;380:247-57.

5. Tremblay MS, Warburton DE, Janssen I, et al. New Canadian physical activity guidelines. Appl Physiol Nutr Metab 2011;36:36-46.

6. Colley RC, Garriguet D, Janssen I, et al. Physical activity of Canadian children and youth: accelerometer results from the 2007 to 2009 Canadian health measures survey. Health Rep 2011;22:15-23.

7. Timperio A, Crawford D, Telford A, et al. Perceptions about the local neighborhood and walking and cycling among children. Prev Med 2004;38:39-47.

8. Hume C, Salmon J, Ball K. Children's perceptions of their home and neighborhood environments, and their association with objectively measured physical activity: a qualitative and quantitative study. Health Educ Res 2005;20:1-13.

9. Evenson KR, Birnbaum AS, Bedimo-Rung AL, et al. Girls' perception of physical environmental factors and transportation: reliability and association with physical activity and active transport to school. Int $J$ Behav Nutr Phys Act 2006;3:1-16.

10. Centers for Disease Control and Prevention. Physical activity levels among children aged 9 to 13 years. Morbidity \& Mortality Weekly Report 2003;785-8.

11. Romero AJ, Robinson TN, Kraemer HC, et al. Are perceived neighborhood hazards a barrier to physical activity in children? Arch Pediatr Adolesc Med 2001:155:1143-8.

12. Molnar BE, Gortmaker SL, Bull FC, et al. Unsafe to play? Neighborhood disorder and lack of safety predict reduced physical activity among urban children and adolescents. Am J Health Promot 2004; 18:378-86.

13. Centers for Disease Control and Prevention (CDC). . School transportation modes-Georgia, 2000. MMWR Morb Mortal Wkly Rep 2002;51:704-5.

14. Ding D, Sallis JF, Kerr J, et al. Neighborhood environment and physical activity among youth: a review. Am J Prev Med 2011;41: 442-55.

15. Edwardson CL, Gorely T. Parental influences on different types and intensities of physical activity in youth: a systematic review. Psychol Sport Exerc 2010;11:522-35.

16. Craggs $\mathrm{C}$, Corder K, van Sluijs EM, et al. Determinants of change in physical activity in children and adolescents: a systematic review. Am J Prev Med 2011;40:645-58.

17. Peel MC, Finlayson BL, McMahon TA. Updated world map of the Köppen-Geiger climate classification. Hydrol Earth Syst Sci 2007;11:1633-44.

18. Kolle E, Steene-Johannessen J, Andersen LB, et al. Seasonal variation in objectively assessed physical activity among children and adolescents in Norway: a cross-sectional study. Int J Behav Nutr Phys Act 2009;6:36.

19. Kristensen PL, Korsholm L, Møller NC, et al. Sources of variation in habitual physical activity of children and adolescents: the European youth heart study. Scand J Med Sci Sports 2008;18:298-308.

20. McCormack GR, Friedenreich C, Shiell A, et al. Sex and age-specific seasonal variations in physical activity among adults. J Epidemiol Community Health 2010;64:1010-16.

21. Carson V, John SC, Cutumisu N, et al. Seasonal variation in physical activity among preschool children in a northern Canadian city. Res Q Exerc Sport 2010;81:392-9.

22. Merchant AT, Dehghan M, Akhtar-Danesh N. Seasonal variation in leisure-time physical activity among Canadians. Can J Public Health 2007;98:203-8.

23. Frittis HC, Lough JM. An estimate of average annual temperature variations for North America, 1602 to 1961. Climatic Change 1985;7:203-24.

24. Zhang $X$, Vincent LA, Hogg WD, et al. Temperature and precipitation trends in Canada during the 20th century. Atomosphere Ocean 2000;38:395-429.

25. Bélanger M, Gray-Donald K, O'Loughlin J, et al. Influence of weather conditions and season on physical activity in adolescents. Ann Epidemiol 2009;19:180-6.

26. Harrison F, Jones AP, Bentham G, et al. The impact of rainfall and school break time policies on physical activity in 9-10 year old British children: a repeated measures study. Int J Behav Nutr Phys Act $2001 ; 8: 47$

27. Sheridan SC. The redevelopment of a weather-type classification scheme for North America. Int J Climatol 2002;22:51-68.

28. City of Saskatoon. Saskatoon Census Metropolitan Area. 2011. http://www.saskatoon.ca/DEPARTMENTS/Community\%20Services/ PlanningDevelopment/FutureGrowth/DemographicAndHousingData/ Documents/2013\%20Neighbourhood\%20Profiles/saskatoon\% 20cma.pdf (accessed 14 Jan 2015).

29. Muhajarine N. Planning for growth in Saskatoon: past, present and future. 2011. http://smartcitieshealthykids.com/wp-content/uploads/ 2013/04/Planning-for-Growth_FINAL_-Aug_20_2012.pdf (accessed 18 Jan 2015).

30. Gauvin L, Richard L, Craig CL, et al. Walkability to active living potential: an "ecometric" validation study. Am J Prev Med 2005;28:126-33.

31. Day K, Boarnet M, Alfonzo M, et al. The Irvine-Minnesota inventory to measure built environments: development. Am J Prev Med 2006;30:144-52.

32. City of Saskatoon. Neighbourhood profiles. 2014. http://www. saskatoon.ca/DEPARTMENTS/Community\%20Services/ PlanningDevelopment/FutureGrowth/DemographicAndHousingData/ Pages/NeighbourhoodProfiles.aspx (accessed 20 Dec 2014). 
33. Generation5. 2010 G5 Census projections. 2014. http://www. generation5.ca/ (accessed 20 Dec 2014).

34. Orme M, Wijndaele K, Sharp SJ, et al. Combined influence of epoch length, cut-point and bout duration on accelerometry-derived physical activity. Int J Behav Nutr Phys Act 2014;11:34.

35. Toftager M, Kristensen PL, Oliver M, et al. Accelerometer data reduction in adolescents: Effects on sample retention and bias. Int $J$ Behav Nutr Phys Act 2013;10:140.

36. Freedson P, Pober D, Janz KF. Calibration of accelerometer output for children. Med Sci Sports Exerc 2005;37:S523-30.

37. Colley R, Connor Gorber S, Tremblay MS. Quality control and data reduction procedures for accelerometry-derived measures of physical activity. Health Rep 2010;21:63-9.

38. Troiano R, Berrigan D, Dodd KW, et al. Physical activity in the United States measured by accelerometer. Med Sci Sports Exerc 2008;40:181-8.

39. Katapally TR, Muhajarine N. Towards uniform accelerometry analysis: a standardization methodology to minimize measurement bias due to systematic accelerometer wear-time variation. J Sports Sci Med 2014;13:379-86.

40. Katapally TR, Muhajarine N. Capturing the Interrelationship between Objectively Measured Physical Activity and Sedentary Behaviour in Children in the Context of Diverse Environmental Exposures. Int $J$ Environ Res Public Health 2015;12:10995-1011.

41. Government of Canada. Daily Data Report for April. 2010. http:// climate.weather.gc.ca/climateData/dailydata e.html? timeframe $=2 \&$ Prov $=S A S K \&$ StationI $D=47707 \&$ dlyRange $=2008-12-$ 02|2014-01-19\&Year=2010\&Month $=4 \& D a y=01$ (accessed 11 Dec 2014)
42. Government of Canada. Sunrise/sunset calculator. 2014. http://www.nrc-cnrc.gc.ca/eng/services/sunrise/ (accessed 11 Dec 2014).

43. Paul AH. Climate and Weather. In: Thraves BD, Lewry ML, Dale JE, et al. eds. Saskatchewan: Geographic perspective. Regina: Canadian Plains Research Center, 2007:37-44.

44. Environment Canada. Canadian Climate Normals 1971-2000 Station Data (Saskatoon Diefenbacker International Airport, Saskatchewan). 2014. http://climate.weather.gc.ca/climate_normals/. (accessed 30 Mar 2014).

45. Rainham DG, Smoyer-Tomic KE, Sheridan SC, et al. Synoptic weather patterns and modification of the association between air pollution and human mortality. Int $J$ Environ Health Res 2005;15:347-60.

46. Esliger D, Sherar L, Muhajarine N. Smart Cities, Healthy Kids: relationship between neighbourhood design and physical activity and sedentary behaviours of children in Saskatoon. Can J Public Health 2012;103:522-8.

47. Prince SA, Tremblay MS, Prud'homme D, et al. Neighbourhood differences in objectively measured physical activity, sedentary time and body mass index. Open J Prev Med 2011;1:182-9.

48. Biddle SJ, Gorely T, Marshall SJ, et al. The prevalence of sedentary behavior and physical activity in leisure time: a study of Scottish adolescents using ecological momentary assessment. Prev Med 2009;48:151-5.

49. Cooper AR, Page AS, Wheeler BW, et al. Mapping the walk to school using accelerometry combined with a global positioning system. Am J Prev Med 2010;38:178-83. 